Article

\title{
Fidelity of Sugarcane Crosses Assessed with SSR Markers
}

\author{
James Todd ${ }^{1}$, Yong-Bao Pan ${ }^{1, *}$ and Deborah Boykin ${ }^{2}$ \\ 1 USDA-ARS, SEA, Sugarcane Research Unit, 5883 USDA Road, Houma, LA 70360, USA; \\ james.todd2@usda.gov \\ 2 USDA-ARS, SEA, Jamie Whitten Delta States Research, 141 Experiment Station Road, \\ Stoneville, MS 38776, USA; debbie.boykin@usda.gov \\ * Correspondence: yongbao.pan@usda.gov
}

Received: 30 January 2020; Accepted: 10 March 2020; Published: 12 March 2020

check for updates

\begin{abstract}
Sugarcane (Saccharum hybrids spp.) is a wind-pollinated species that bears very small yet complete flowers. During crossing, a lack of pollen control (trimming off dehisced florets and hot water treatment) may result in both self-pollination (selfs) and unintentional pollination from stray pollen (off-types). Due to this uncertainty, it is important to estimate the percentage of intentional paternal hybridizations to better understand and possibly improve the crossing process. In this study, six pairs of simple sequence repeats (SSR) primers were used to assess the fidelity of 343 bi-parental crosses made at three U.S. breeding stations in 2002, 2003, 2004, 2005, and 2006. By comparing the SSR fingerprints between the two parents and 20 random progenies, three types of progenies were identified, namely, hybrids, selfs, and off-types. Hybrids had only SSR fingerprints found in either parent; selfs had only SSR fingerprints of the maternal parent; and off-types had SSR fingerprints that were not found in either parent. The fidelity of the 343 crosses fluctuated from $100 \%$ hybrids to $100 \%$ off-types. Multinomial analysis indicated that the ratio of hybrids from intentional hybridization to selfs and off-types fluctuated by year and location. Selfing rates $(-30.5 \%)$ and off-type rates $(-9.2 \%)$ were lower in crosses from which superior progenies were selected and advanced through 10-year field evaluation and testing, but off-type rates were not significant indicating that selfing may reduce advancement rates more than the off-types. Hot water treatment reduced off-types by $27 \%$ and selfing by $20 \%$. This research demonstrates the utility of SSR markers for measuring hybridization rates and highlights the importance of pollen control measures through trimming and hot water treatment of sugarcane flowers.
\end{abstract}

Keywords: sugarcane breeding; cross fidelity; Saccharum hybrids spp.; SSR

\section{Introduction}

In the beginning of 20th century, the first series of modern sugarcane cultivars was produced by crossing $S$. officinarum with $S$. spontaneum, followed by "Nobilization" of the inter-specific hybrids by continuous backcrossing to $S$. officinarum and selection to incorporate genetic diversity through introgression with $S$. spontaneum [1,2]. Since then, sugarcane breeders have been conducting both biparental- or poly-crosses [1] to pursue their breeding objectives, such as increasing yield in tonnes of cane per hectare, tonnes of sucrose per hectare, sucrose content, and disease resistance. Sugarcane breeding in Louisiana is divided into the introgression program that incorporates genetic diversity from S. spontaneum or other wild material and the commercial program that develops new commercial cultivars [3]. In both programs, in order to maintain correct breeding records and/or genetic diversity it is necessary to make crosses accurately. 
Sugarcane biparental crosses are defined as the cross pollination of two known parental clones often involving one clone which produces good pollen as "male" and the other as "female". However, sugarcane crossing is long and complex, and is best envisioned as a continuous process involving a large number of photoperiod controlled steps, in which errors such as off-type or selfed seeds are made easily. Off-type seeds are produced by stray pollen from unintentional parents [4]. Mistakes that are made during sugarcane flower collection and storage also may increase off-type progeny. Sugarcane can also self-pollenate, particularly if excess pollen is in the vicinity. Several studies utilizing molecular markers have assessed parent identity, percent outcrossing, and the level of self-pollination from sugarcane crossing [5-12].

Molecular markers are based on naturally occurring polymorphisms in DNA sequences (i.e., base pair deletions, additions, or patterns). There are various methods to detect and amplify these polymorphisms for use in breeding analysis. The simple sequence repeats (SSRs, also called microsatellites) method is one type of molecular marker and has the advantage of being highly polymorphic, highly abundant, with co-dominant inheritance, and analytically simple and readily transferable [13]. Microsatellites are often used to determine intentional hybridization (hybrids), selfing, and contamination in sugarcane seedlings [6-8,10-12]. Microsatellites or simple sequence repeat (SSR) markers have been successfully used to identify hybrids [14-16] and nucellar seedlings [17] in citrus and sugarcane hybrids [18]. Hack et al. [12] used SSR markers to determine the pedigree of a sugarcane cross made in South Africa. In their study, the number of non-parental markers found in a sample of 10 progeny from 8 crosses ranged from 6 to 18. Although they were not able to identify the parents of the cross, this study did show the potential of SSR markers to determine off-types from crosses. Tew and Pan [10] measured the contribution of the male parent in seven parent polycrosses and found that selfs ranged from $0 \%$ to $45 \%$ and off-types ranged from $0 \%$ to $18 \%$. Melloni et al. [6] evaluated a polycross of four sugarcane cultivars. Out of 154 progenies from two female parents, 22 were intentional hybrids, four were off-types, and 131 were selfs. Costa et al. [7] intentionally self-pollinated five cultivars; however, the proportion of selfed seeds ranged from $71.7 \%$ to $83.3 \%$. Santos et al. [8] measured selfing, hybrid, and off-type rates among 76 progenies from four bi-parental crosses. Although no selfed progeny was found, off-type progenies occurred at $0 \%$ to $80 \%$. Xavier et al. [11] performed a similar polycross study with four large polycrosses in Brazil and identified the male parent in $73 \%$ of the progenies with no selfing. These studies indicate that the percentage of intentional hybridization, selfing, and off-types varies strongly by cross. The segregation ratios of DNA markers among sugarcane pollen grains were measured [15,16]; although some unusual segregation ratios were found, only a few non-parental DNA amplifications were found in both studies with two out of 92 pollens in Pan et al. [15] and only one out of 2392 pollens in Lu et al. [16] . This indicates that SSRs are very stable in sugarcane. The results from this past research indicate that the combination of visual selection and SSR markers could be an efficient method to identify hybrids derived from sugarcane crosses. These past studies focused on a relatively small number of crosses and did not look at patterns of crossing when a large number of crosses was made over several years and across several breeding stations.

In the present study, we aimed to fill in this gap by evaluating the fidelity of 343 sugarcane biparental crosses made in five years at three different locations using SSR markers. The correlation between cross fidelity and number of progenies selected and new breeding lines assigned was also determined.

\section{Materials and Methods}

\subsection{Plant Material}

In total, 346 sugarcane biparental crosses made in 2002, 2003, 2004, 2005, and 2006 were randomly selected for cross fidelity assessment at the seedling stage in 2003, 2004, 2005, 2006, and 2007, respectively. Seedling selection and advancement data were collected through 10-year field evaluation and testing 
to determine if there is any correlation between cross fidelity and breeding advancement. The United States Department of Agriculture (USDA) sugarcane crossing for Louisiana breeding occurs both at the USDA-ARS, Sugarcane Research Unit (RSU) in Houma, LA (Houma), and the USDA-ARS, Sugar Field Station in Canal Point, FL (Canal Point). Crossing also occurs at the Louisiana State University Ag Center Research Station in St. Gabriel (LSU) as part of a separate breeding program, which shares in the evaluation of plants in the later stages as part of a three-way agreement with the USDA-ARS, the American Sugarcane League, and the LSU Ag Center. From these three locations, crosses were sampled including: 176 at the USDA-ARS, Sugarcane Research Unit, Houma, LA; 51 crosses were made at Louisiana State University Ag Center Research Station in St. Gabriel; and 135 crosses were made at the USDA-ARS, Sugar Field Station, Canal Point, FL and were evaluated by SSR analysis. Respective breeder(s) at each location made the crosses. In general, flower tassels with approximately 10-15 cm emergence (about 2 months after flower initiation) were collected. Males were assigned by microscope or magnifying glass based on abundance of pollen production. Cubicles were used at each location, and two of the locations (Canal Point and Houma) had doors or cloth barriers in front of the cubicles. Tassel trimming and hot water treatment were conducted only at USDA-ARS, SRU, Houma, LA. For each cross, a 20-seedling sample was randomly selected from germination trays for quick DNA extraction and SSR fingerprinting. Of the 363 crosses evaluated, 337 were planted into the field for evaluation and selection.

\subsection{Nucleic Acid Extraction}

Twenty seedlings were sampled per cross. Total nucleic acids were extracted from the leaf pieces following the HT-DNA extraction procedure developed by Xin et al. [19]. Genomic DNA of the two parents, positive control (LCP 85-384 [20], with known SSR pattern) and negative control (sterile water) were included.

\subsection{Primers, Reaction Mixture, PCR Program, and Capillary Electrophoresis}

Based on information from an SSR molecular identity database [21], six SSR primer pairs from the International Consortium of Sugarcane Biotechnologists [18] were selected that produced the maximum number of male parent-specific SSR fingerprints (Table 1). All forward primers were labeled with a fluorescent phosphoramidite dye, namely, FAM ${ }^{\mathrm{TM}}, \mathrm{NED}^{\mathrm{TM}}$, or VIC ${ }^{\mathrm{TM}}$ (Applied Biosystems, Inc., Foster City, CA, USA). The PCR reaction mixture and thermal cycling program were conducted according to Pan [22] with annealing temperatures varied by SSR markers (Table 1). In brief, the reaction mixture consisted of $0.25 \mu \mathrm{L}$ of HT-DNA sample, $0.5 \mu \mathrm{L}$ of 10X Buffer, $0.3 \mu \mathrm{l}$ of $25 \mathrm{mM} \mathrm{MgCl}$, $0.1 \mu \mathrm{L}$ of $10 \mathrm{mM}$ dNTPs, $0.41 \mu \mathrm{l}$ each of $3 \mathrm{pm} / \mu \mathrm{l}$ forward and reverse primers, $0.5 \mu \mathrm{l}$ of $10 \mathrm{mg} / \mathrm{mL}$ BSA-V, $0.5 \mu \mathrm{L}$ of $100 \mathrm{mg} / \mathrm{mL}$ PVP-40, $0.025 \mu \mathrm{l}$ of 5 units $/ \mu \mathrm{L}$ Taq polymerase, and $2.0 \mu \mathrm{l}$ of sterile water. The thermal cycling program was $95^{\circ} \mathrm{C}$ for $15 \mathrm{~min}, 40$ cycles of $\left(94^{\circ} \mathrm{C}\right.$ for $15 \mathrm{~s}$, annealing for $15 \mathrm{~s}$, and $72{ }^{\circ} \mathrm{C}$ for $1 \mathrm{~min}$ ), final extension at $72{ }^{\circ} \mathrm{C}$ for $10 \mathrm{~min}$, and holding at $4{ }^{\circ} \mathrm{C}$. PCR products were separated through capillary electrophoresis along with Rox ${ }^{\mathrm{TM}} 500$ size standards following the manufacturer's instructions (Applied Biosystems, Inc., Foster City, CA, USA) to generate GeneScan files. 
Table 1. Simple sequence repeat (SSR) primer pairs used to identify sugarcane seedlings hybrid.

\begin{tabular}{|c|c|c|c|c|c|}
\hline Name & $\begin{array}{c}\text { SSR } \\
\text { Repeat }\end{array}$ & Number of Bands & Size Range (Base Pairs) & Annealing ${ }^{\circ} \mathrm{C}$ & $\begin{array}{l}\text { Forward Primer Sequence }\left(5^{\prime} \text { to } 3^{\prime}\right) \\
\text { Reverse Primer Sequence }\left(3^{\prime} \text { to } 5^{\prime}\right)\end{array}$ \\
\hline SMC334BS & $(\mathrm{TG})_{36}$ & 13 & $140-170$ & 60 & $\begin{array}{l}\text { CAA TTC TGA CCG TGC AAA GAT } \\
\text { CGA TGA GCT TGA TTG CGA ATG }\end{array}$ \\
\hline SMC336BS & $(\mathrm{TG})_{23}(\mathrm{AG})_{19}$ & 24 & 140-190 & 62 & $\begin{array}{l}\text { ATT CTA GTG CCA ATC CAT CTC A } \\
\text { CAT GCC AAC TTC CAA ACA GAC }\end{array}$ \\
\hline SMC1604SA & $(\mathrm{TGC})_{7}$ & 7 & $100-130$ & 58 & $\begin{array}{l}\text { AGG GAA AAG GTA GCC TTG G } \\
\text { TTC CAA CAG ACT TGG GTG G }\end{array}$ \\
\hline SMC597CS & $(\mathrm{AG})_{31}$ & 19 & $140-170$ & 64 & $\begin{array}{l}\text { GCA CAC CAC TCG AAT AAC GGA T } \\
\text { AGT ATA TCG TCC CTG GCA TTC A }\end{array}$ \\
\hline SMC18SA & $(\mathrm{CGA})_{10}$ & 7 & $140-150$ & 62 & $\begin{array}{l}\text { ATT CGG CTC GAC CTC GGG AT } \\
\text { AGT CGA AAG GTA GCG TGG TGT TAC }\end{array}$ \\
\hline SMC703BS & $(\mathrm{CA})_{12}$ & 15 & $200-220$ & 62 & $\begin{array}{l}\text { GCC TTT CTC CAA ACC AAT TAG T } \\
\text { GTT GTT TAT GGA ATG GTG AGG A }\end{array}$ \\
\hline
\end{tabular}




\subsection{SSR Markers Analysis}

The GeneScan raw files were analyzed with GeneMapper ${ }^{\circledR}$ software (v3.0) (Applied Biosystems Inc., Foster City, CA, USA) to produce capillary electrophoregrams of amplified DNA fragments according to Pan [22]. In this study, alleles were manually assigned to regular fluorescence peaks and their sizes were calibrated against the GeneScan-500 size standards. Several types of irregular peaks including "stutters", "pull-ups", "dinosaur tails", or "minus-A peaks" were not scored in this study. The presence of a particular peak, or allele, was given a score " 1 ". The fingerprints of both parents and the 20 progenies were compared. If a progeny only produced SSR fingerprints from both parents or from its male parent, then the progeny was classified as $F_{1}$ hybrid. Progenies producing SSR fingerprints only from the female parent were classified as selfs. If a progeny produced any fingerprint that was not produced by the designated parents, it was defined as an off-type. An example is given in Table 2 for Cross HB 04-3305 involving two SSR markers, SMC336BS with four parental alleles $(166,169,171$, and 177) and SMC597BS with six parental alleles $(144,148,161,164,165$, and 168). In addition, five alleles of SMC336BS $(141,167,172,175$, and 178) and two alleles of SMC597BS (157 and 166) were detected among the four off-type seedlings \#1,\#9, \#11, and \#16, which were not amplified by either parent; two selfs, \#4 and \#19, only amplified SSR alleles of the maternal parent CP 89-831. For the remaining hybrid seedlings, at least one SSR allele of the paternal parent HoCP 96-540 was present. As aneuploid polyploids, it is expected that multiple alleles are amplifiable from one sugarcane genotype and the resolution power of our fluorescence labeling and capillary electrophoresis-based SSR fingerprinting platform is one base pair [21]. However, the inheritance of SSR markers in sugarcane seems to be very complicated and remains a challenge [15,16]. 
Table 2. Identification of Cross HB 04-3305 using SSR markers. Three types of progeny were identified from the Cross HB 04-3305, the first type is hybrid (H), the second type is self (S), the third type is off-type (x).

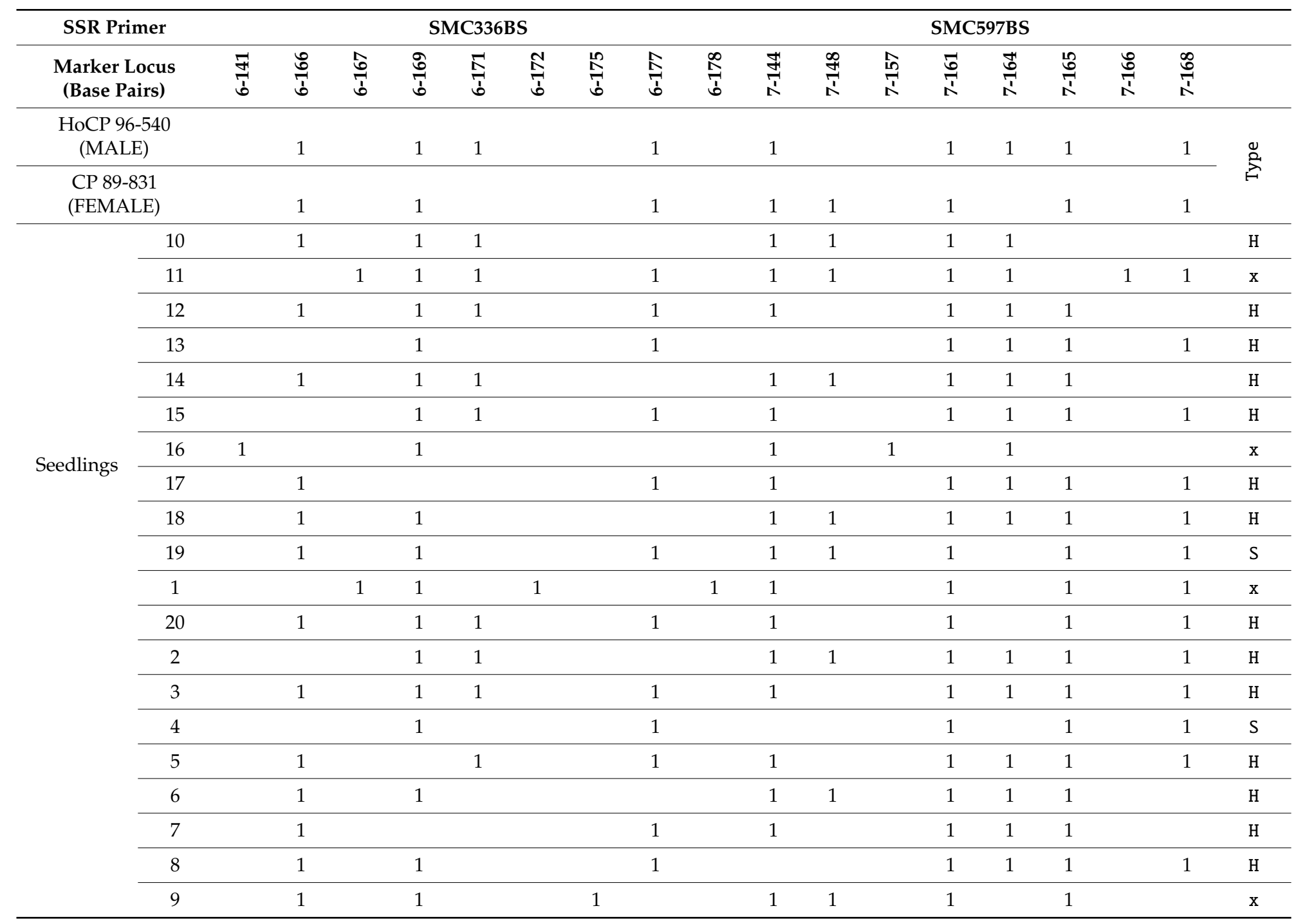


Table 2. Cont.

\begin{tabular}{|c|c|c|c|c|c|c|c|c|c|c|c|c|c|c|c|c|c|}
\hline \multirow{2}{*}{$\begin{array}{c}\text { SSR Primer } \\
\text { Marker Locus } \\
\text { (Base Pairs) }\end{array}$} & \multirow[b]{2}{*}{$\frac{7}{7}$} & \multicolumn{7}{|c|}{ SMC336BS } & \multicolumn{9}{|c|}{ SMC597BS } \\
\hline & & 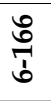 & $\begin{array}{l}\hat{t} \\
\qquad \mathfrak{b}\end{array}$ & $\frac{8}{\frac{8}{1}}$ & $\frac{\sqrt{\sigma}}{6}$ & ำ & $\frac{10}{\frac{10}{6}}$ & $\frac{\hat{N}}{\widehat{b}}$ & $\frac{\infty}{\widehat{c}}$ & 吉 & 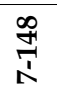 & $\begin{array}{l}\hat{1} \\
\frac{1}{1}\end{array}$ & 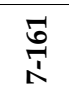 & $\begin{array}{l}\text { J } \\
\stackrel{1}{1}\end{array}$ & $\begin{array}{l}10 \\
\stackrel{1}{1} \\
\end{array}$ & $\begin{array}{l}\stackrel{0}{0} \\
\stackrel{1}{1}\end{array}$ & $\begin{array}{l}\infty \\
0 \\
\\
1\end{array}$ \\
\hline \multicolumn{10}{|c|}{ Selfs (\%) } & \multicolumn{8}{|c|}{$2(10)$} \\
\hline \multicolumn{10}{|c|}{ Off-types (\%) } & \multicolumn{8}{|c|}{$4(20)$} \\
\hline \multicolumn{10}{|c|}{ Hybrid (\%) } & \multicolumn{8}{|c|}{$14(70)$} \\
\hline
\end{tabular}




\subsection{Rate of Seedling Selection and Assignment}

Seedlings were germinated in the greenhouse, planted the year after crossing, and selections were in the following year's regrowth. Selections were planted as first line trials. The next year second line trials were selected from first line trials. In two years, selection was made of assignments from second line trials in the first ratoon [23]. Assignments were then taken off station for further yield evaluation. A detailed summary of a complete 12-year breeding cycle can be found in Tew et al. [23].

\subsection{Identification of Hybrids, Selfs, and Off-Types among All Tested Seedlings from Biparental Crosses}

Using the aforementioned methods, 343 sugarcane biparental crosses were assessed, including 2 in 2002, 30 in 2003, 69 in 2004, 122 in 2005, and 120 in 2006. In total, 6951 seedlings were assessed (Table 3), including: 40 seedlings from 2002, 600 from 2003, 1378 from 2004, 2509 from 2005, and 2424 from 2006. More seedlings from crosses made in Houma were evaluated in 2004 than crosses made at Canal Point or LSU (Table 3). Only one cross from LSU was evaluated in 2002 and 2004. In 2005 and 2006, a similar number of seedlings from Canal Point and Houma was evaluated with Canal Point having approximately 300 to 200 less. LSU had half to a third of the other locations evaluated in 2005 and 2006. 
Table 3. Identification of hybrids, selfs, and off-types among 7200 seedlings in 2002, 2003, 2004, 2005, and 2006 and the total.

\begin{tabular}{|c|c|c|c|c|c|c|c|c|}
\hline \multicolumn{9}{|c|}{ Total } \\
\hline Year & Hybrids & $\% \mathrm{H}+$ & Selfs & $\% \mathrm{~S} \ddagger$ & Off-types & $\% C \S$ & Total & Assign \\
\hline 2002 & 26 & 65 & 1 & 2.5 & 13 & 32.5 & 40 & 2 \\
\hline 2003 & 231 & 38.5 & 91 & 15.2 & 278 & 46.3 & 600 & 4 \\
\hline 2004 & 776 & 56.3 & 315 & 22.9 & 287 & 20.8 & 1378 & 19 \\
\hline 2005 & 1448 & 57.7 & 686 & 27.3 & 375 & 14.9 & 2509 & 8 \\
\hline 2006 & 1579 & 65.1 & 669 & 27.6 & 176 & 7.3 & 2424 & 2 \\
\hline Total & 4060 & 58.4 & 1762 & 25.3 & 1129 & 16.2 & 6951 & 35 \\
\hline \multicolumn{9}{|c|}{ Canal Point } \\
\hline 2002 & 13 & 65 & 0 & 0 & 7 & 35 & 20 & 2 \\
\hline 2003 & 98 & 27.2 & 54 & 15 & 208 & 57.8 & 360 & 2 \\
\hline 2004 & 206 & 72.3 & 20 & 7.0 & 59 & 20.7 & 285 & 4 \\
\hline 2005 & 555 & 66.1 & 198 & 23.6 & 87 & 10.4 & 840 & 5 \\
\hline 2006 & 708 & 73.8 & 214 & 22.3 & 38 & 4.0 & 960 & 2 \\
\hline Total & 1580 & 64.1 & 486 & 19.7 & 399 & 16.2 & 2465.0 & 15.0 \\
\hline \multicolumn{9}{|c|}{ Houma } \\
\hline 2003 & 63 & 52.5 & 9 & 7.5 & 48 & 40 & 120 & 0 \\
\hline 2004 & 567 & 59.1 & 171 & 17.8 & 221 & 23.0 & 959 & 15 \\
\hline 2005 & 689 & 58.9 & 306 & 26.2 & 174 & 14.9 & 1169 & 3 \\
\hline 2006 & 674 & 60.0 & 353 & 31.4 & 97 & 8.6 & 1124 & 0 \\
\hline Total & 1993 & 59.1 & 839 & 24.9 & 540 & 16 & 3372 & 18 \\
\hline \multicolumn{9}{|c|}{ LSU } \\
\hline 2002 & 13 & 65 & 1 & 5 & 6 & 30 & 20 & 0 \\
\hline 2003 & 70 & 58.3 & 28 & 23.3 & 22 & 18.3 & 120 & 2 \\
\hline 2004 & 3 & 15 & 10 & 50 & 7 & 35 & 20 & 0 \\
\hline 2005 & 204 & 40.8 & 182 & 36.4 & 114 & 22.8 & 500 & 0 \\
\hline 2006 & 197 & 57.9 & 102 & 30 & 41 & 12.1 & 340 & 0 \\
\hline Total & 487 & 48.7 & 323 & 32.3 & 190 & 19 & 1000 & 2 \\
\hline
\end{tabular}

† Percent intentional hybrids; $\ddagger$ Percent selfing; § Percent off-types; Selected and given a permanent number in the second stage of the breeding program. 


\subsection{Statistical Analysis}

For each cross, the frequency (or percent) of seedlings classified as hybrid, selfs, or off-types had a multinomial distribution. Analysis of variance (ANOVA) was used to see if the percent of seedlings in each type was the same for each year with the type as the dependent response variable and year as the independent fixed variable. The intercept was treated as a random effect with type as a group contrast. The ANOVA was based on a generalized linear mixed model with type having a multinomial distribution with ordered categories and a generalized logit link function [24] using SAS Proc GLIMMIX in SAS version 9.4 software [25]. This analysis was done for all the locations and within each individual location. Additionally, to see if assignment was affected by percent hybrids, the analysis was redone with year, assignment status, and their interaction as the independent fixed variables not including data for the small number of crosses evaluated from 2002, and only the 279 crosses that were planted into the field. From this the percent of each year and binary assignment status were estimated to see if assignment was affected by hot water treatment which sterilizes the male portion of the tassel. This was only done at the USDA Houma location. Hot water treatment was added to the analysis and was done combined with assignment and hot water treatment and their interaction and separately by hot water treatment.

\section{Results and Discussion}

\subsection{Identification of Hybrids, Selfs, and Off-Types from Sugarcane Biparental Crosses}

Polymorphism was clearly observed with the six SSR primer pairs and the number of sequence repeats, size range, and annealing temperature (Table 1). An example of a cross (HB 04-3305) is in Table 2, in which hybrids, selfs, and off-types were identified by SSR primer pairs SMC 336 and SMC 597. Seedlings 1, 9, 11, and 16 had alleles which could not be accounted for in the male (HoCP 96-540) or female parent (CP 89-831) and were assessed to be off-types. Seedlings 4 and 9 only had alleles that were found in the female parent CP 89-83 and were considered selfs. The rest of the 14 seedlings were assessed to be hybrids with the intended parents, HoCP 96-540 and CP 89-831. It could be concluded that there were 14 hybrids (70\%), 2 selfs (10\%), and 4 off-types $(20 \%)$ among the 20 seedlings from sugarcane cross HB 04-3305. Through this method, the cross quality for five years-2002, 2003, 2004, 2005, and 2006-was assessed using the six SSR markers (Table 3).

\subsection{Analysis of Hybrids, Selfs, and Off-Types among All Tested Seedlings from Biparental Crosses}

The percentage of hybrids, selfs, and off-types in 2003, 2004, 2005, 2006 and total four years and for all three breeding programs is listed in Table 3. There were only two crosses evaluated from 2002 including one from Houma and the other from LSU. The cross information from 2002 was ignored in year comparisons. The percentage of hybrids, selfs, and off-types varied by year and location, indicating that specific crossing practices, conditions, and parental genotypes strongly affected hybridization. Practices include: keeping high pollen parents away from parents treated as female; curtains that separate flowering booths from each other; and hot water treating tassels to sterilize them and prevent selfing. Canal Point had a wider range of percentages for hybrids that ranged from approximately $27 \%$ to $74 \%$ with 2003 as an outlier with a lower percentage of hybrids $(27 \%)$ than the other years which ranged from $64-74 \%$. Houma was somewhat more consistent between years, being $53 \%$ for $2003,59 \%$ for $2004,59 \%$ for 2005 , and $60 \%$ for 2006. In 2005, the percentage of hybrids of LSU seedlings was $41 \%$, which was lower than the seedlings from the other two programs. LSU seedlings also had a high percentage of selfs (36\%) in 2005, but a similar rate of hybrids (58\%) and selfs $(23 \%)$ to the other programs (30\%) in 2003 and 2006. Excluding the single cross from LSU in 2004, selfs ranged from $20-41 \%$. With the exception of the single cross from LSU in 2004, the percent of off-types was relatively low across all locations in the years 2004-2006, ranging from $4 \%$ to $23 \%$. In 2003, Canal Point and Houma had a high percentage of off-types with approximately $58 \%$ and $40 \%$ off-types, respectively. This could be due to the crossing practices performed at that time. Crossing is also 
affected by conditions during crossing including temperature and humidity, but the effect of conditions on pollination has a genotype by environment interaction that has not been fully studied with the genotypes in this study [26]. The results indicate variable rates of precision for the sugarcane biparental crosses, which overall averaged $58.4 \%$ hybrids.

Least squares means were not produced from ANOVA because seedling type (selfs, hybrid, or outcross) as a response measurement has a multinomial distribution. Odds ratios are used compare the percentage of seedings in each type between years [24]. For example, from Table 4 we show that the probability of getting an off-type seedling was 3.25 times more likely in 2003 than in 2004. More specifically, odds ratio = odds of getting off-type seedlings vs. hybrid seedlings in 2003 and odds of getting off-type seedlings vs. hybrid seedlings in $2004=3.25$.

Table 4. Odds ratio estimates for total crosses made at Canal Point, FL; Houma, LA; and St. Gabriel, LA (Louisiana State University, LSU) during 2003-2006. Parental status including intentional hybridization $(\mathrm{H})$, selfing (S), or unintentional outcross (C) was determined for a random sample of 20 from each cross.

\begin{tabular}{ccccccc}
\hline \multicolumn{7}{c}{ Total } \\
\hline Type & Target Year & Comparison & Ratio & Confidence Interval & \% Change \\
\hline $\mathrm{C} / \mathrm{H} \dagger$ & 2003 & 2004 & 3.25 & 2.61 & 4.06 & $225.4^{*}$ \\
$\mathrm{~S} / \mathrm{H} \ddagger$ & 2003 & 2004 & 0.97 & 0.74 & 1.28 & -3.0 \\
$\mathrm{C} / \mathrm{H}$ & 2003 & 2005 & 4.49 & 3.65 & 5.54 & $349.4^{*}$ \\
$\mathrm{~S} / \mathrm{H}$ & 2003 & 2005 & 0.80 & 0.62 & 1.04 & -19.7 \\
$\mathrm{C} / \mathrm{H}$ & 2003 & 2006 & 10.80 & 8.55 & 13.64 & $979.7^{*}$ \\
$\mathrm{~S} / \mathrm{H}$ & 2003 & 2006 & 0.93 & 0.72 & 1.21 & -7.0 \\
$\mathrm{C} / \mathrm{H}$ & 2004 & 2005 & 1.38 & 1.16 & 1.65 & $38.1^{*}$ \\
$\mathrm{~S} / \mathrm{H}$ & 2004 & 2005 & 0.83 & 0.71 & 0.97 & $-17.2^{*}$ \\
$\mathrm{C} / \mathrm{H}$ & 2004 & 2006 & 3.32 & 2.70 & 4.08 & $231.8^{*}$ \\
$\mathrm{~S} / \mathrm{H}$ & 2004 & 2006 & 0.96 & 0.82 & 1.12 & -4.2 \\
$\mathrm{C} / \mathrm{H}$ & 2005 & 2006 & 2.40 & 1.98 & 2.91 & $140.2^{*}$ \\
$\mathrm{~S} / \mathrm{H}$ & 2005 & 2006 & 1.16 & 1.02 & 1.32 & $15.7^{*}$ \\
\hline
\end{tabular}

+ Percent odds ratio of off-type to hybrid; $\ddagger$ Percent odds ratio of selfs to hybrid. ${ }^{*}$ indicates significance at $95 \%$ confidence.

According to the odds ratio, the probability of getting an off-type vs. a hybrid was higher in 2004 and 2005 vs. 2006 overall and at all locations (Table 4; Table 5). In addition, 2003 vs. 2006 was significantly higher overall and at Canal Point and Houma (Table 4; Table 5). The rate of selfing also varied. Houma crosses had significantly less selfing in 2004 and 2005 compared with 2006, while the other two locations had higher rates of selfing in 2004 and 2005 than in 2006. In 2005, LSU crosses had significantly more selfs than hybrids compared with 2006. 
Table 5. Odds ratio estimates for crosses made at Canal Point, FL; Houma, LA; and St. Gabriel, LA (LSU) in 2003-2006. Parental status including intentional hybridization (H), selfing (S), or unintentional outcross (C) was identified from a random sample of 20 from each cross. The ratio of off-types and selfing to hybrids was compared between years, so increases or decreases in the percentage of selfs or outcrossed progenies can be identified from the target year.

\begin{tabular}{|c|c|c|c|c|c|c|}
\hline \multicolumn{7}{|c|}{ Canal Point } \\
\hline \multirow{2}{*}{$\frac{\text { Type }}{\mathrm{C} / \mathrm{H}}$} & \multirow{2}{*}{$\frac{\text { Target Year }}{2003}$} & \multirow{2}{*}{$\begin{array}{c}\text { Comparison } \\
2004\end{array}$} & \multirow{2}{*}{$\frac{\text { Ratio }}{7.41}$} & \multicolumn{2}{|c|}{ Confidence Interval } & \multirow{2}{*}{$\frac{\text { Percent } \dagger}{641.1^{*}}$} \\
\hline & & & & 5.09 & 10.80 & \\
\hline $\mathrm{S} / \mathrm{H}$ & 2003 & 2004 & 0.85 & 0.57 & 1.26 & -15.3 \\
\hline $\mathrm{C} / \mathrm{H}$ & 2003 & 2005 & 12.49 & 8.95 & 17.41 & $1148.5 *$ \\
\hline $\mathrm{S} / \mathrm{H}$ & 2003 & 2005 & 1.41 & 0.98 & 2.05 & 41.3 \\
\hline $\mathrm{C} / \mathrm{H}$ & 2003 & 2006 & 39.55 & 26.37 & 59.31 & 3854.5 * \\
\hline $\mathrm{S} / \mathrm{H}$ & 2003 & 2006 & 1.82 & 1.26 & 2.63 & $82.3 *$ \\
\hline $\mathrm{C} / \mathrm{H}$ & 2004 & 2006 & 1.69 & 1.16 & 2.44 & $68.5 *$ \\
\hline $\mathrm{S} / \mathrm{H}$ & 2004 & 2006 & 1.67 & 1.27 & 2.19 & $66.8 *$ \\
\hline $\mathrm{C} / \mathrm{H}$ & 2004 & 2005 & 5.34 & 3.45 & 8.26 & $433.6 *$ \\
\hline $\mathrm{S} / \mathrm{H}$ & 2004 & 2005 & 2.15 & 1.65 & 2.81 & $115.2 *$ \\
\hline $\mathrm{C} / \mathrm{H}$ & 2005 & 2006 & 3.17 & 2.12 & 4.72 & 216.7 * \\
\hline $\mathrm{S} / \mathrm{H}$ & 2005 & 2006 & 1.29 & 1.03 & 1.62 & $29 *$ \\
\hline \multicolumn{7}{|c|}{ Houma } \\
\hline $\mathrm{C} / \mathrm{H}$ & 2003 & 2004 & 1.96 & 1.30 & 2.94 & $95.5^{*}$ \\
\hline $\mathrm{S} / \mathrm{H}$ & 2003 & 2004 & 0.47 & 0.23 & 0.97 & $-52.6 *$ \\
\hline $\mathrm{C} / \mathrm{H}$ & 2003 & 2005 & 3.02 & 2.00 & 4.55 & $201.7^{*}$ \\
\hline $\mathrm{S} / \mathrm{H}$ & 2003 & 2005 & 0.32 & 0.16 & 0.66 & -67.8 * \\
\hline $\mathrm{C} / \mathrm{H}$ & 2003 & 2006 & 5.29 & 3.44 & 8.15 & 429.4 * \\
\hline $\mathrm{S} / \mathrm{H}$ & 2003 & 2006 & 0.27 & 0.13 & 0.56 & $-72.7^{*}$ \\
\hline $\mathrm{C} / \mathrm{H}$ & 2004 & 2006 & 1.54 & 1.23 & 1.94 & $54.3^{*}$ \\
\hline $\mathrm{S} / \mathrm{H}$ & 2004 & 2006 & 0.68 & 0.55 & 0.84 & $-32.1 *$ \\
\hline $\mathrm{C} / \mathrm{H}$ & 2004 & 2005 & 2.71 & 2.08 & 3.53 & $170.8^{*}$ \\
\hline $\mathrm{S} / \mathrm{H}$ & 2004 & 2005 & 0.58 & 0.47 & 0.71 & $-42.4^{*}$ \\
\hline $\mathrm{C} / \mathrm{H}$ & 2005 & 2006 & 1.76 & 1.34 & 2.30 & $75.5^{*}$ \\
\hline $\mathrm{S} / \mathrm{H}$ & 2005 & 2006 & 0.85 & 0.70 & 1.02 & -15.2 \\
\hline
\end{tabular}


Table 5. Cont

\begin{tabular}{ccccccc}
\hline \multicolumn{7}{c}{ LSU $\ddagger$} \\
\hline C/H & 2003 & 2004 & 0.14 & 0.03 & 0.57 & $-86.5^{*}$ \\
S/H & 2003 & 2004 & 0.12 & 0.03 & 0.47 & $-88^{*}$ \\
C/H & 2003 & 2005 & 0.56 & 0.33 & 0.96 & $-43.8^{*}$ \\
S/H & 2003 & 2005 & 0.45 & 0.28 & 0.73 & $-55.2^{*}$ \\
C/H & 2003 & 2006 & 1.51 & 0.84 & 2.71 & 51 \\
S/H & 2003 & 2006 & 0.77 & 0.47 & 1.27 & $-22.7^{*}$ \\
C/H & 2004 & 2006 & 4.18 & 1.06 & 16.49 & $317.5^{*}$ \\
S/H & 2004 & 2006 & 3.74 & 1.01 & 13.81 & $273.6^{*}$ \\
C/H & 2004 & 2005 & 11.21 & 2.78 & 45.26 & $1021.1^{*}$ \\
S/H & 2004 & 2005 & 6.44 & 1.73 & 23.95 & $543.8^{*}$ \\
C/H & 2005 & 2006 & 2.69 & 1.79 & 4.04 & $168.5^{*}$ \\
S/H & 2005 & 2006 & 1.72 & 1.26 & 2.35 & $72.3^{*}$ \\
\hline
\end{tabular}

† Percent change; $\ddagger$ only one cross from $2004,{ }^{*}$ indicates significance at $95 \%$ confidence. 
The primary trend was a decrease in off-types from 2003 to 2006. A decrease in selfs was also observed among crosses from Canal Point and LSU; however, an increase in selfs was shown among the Houma crosses during this period. To see if hot water treatment affected the ratio of off-types or hybrids, hot water treatment was added to the analysis at the Houma location. The cane tassels that were hot water treated were approximately $27 \%$ less likely to be an off-type and $20 \%$ less likely to be selfs if hot water treated (Table 6). This indicates that hot water treatment reduces selfing and outcrossing, but these were not large reductions. Since the crosses were selected at random, the exact nature of each individual flower's development stage is unknown. It could be that the tassels were not trimmed before crossing and included florets that opened and were pollenated outside the crossing booth.

Table 6. Percent hybrid (H), selfs (S), and off-type (C) and the percent difference from the odds ratio of off-type to hybrid and selfs to hybrid for hot water treated flowers.

\begin{tabular}{cccccc}
\hline & & & \multicolumn{3}{c}{ Yes vs. No } \\
\hline Hot Water Treated & $\% \mathbf{H}+$ & $\mathbf{\%} \ddagger$ & $\% \mathrm{C} \S$ & $\mathbf{C} / \mathbf{H}$ & $\mathrm{S} / \mathbf{H} \#$ \\
\hline Yes & 59.2 & 25.1 & 15.7 & $-26.9 \%$ * & $-19.9 \%$ * \\
No & 65.2 & 22.2 & 12.7 & & \\
\hline
\end{tabular}

* Indicates significance at 95\% confidence; † Percent intentional hybrids; $\ddagger$ Percent selfing; § Percent off-types; Percent odds ratio of off-type to hybrid; \# Percent odds ratio of self to hybrid.

Assignments were made from individual plants from these crosses. To see if assignments came from families with a disproportionate number of off-types, assignments were used as an explanatory variable in the model. Data from all the years were used in this analysis and year was not included in the model. Only the crosses which were planted were included in the model. According to the odds ratio, the likelihood of selecting an off-type was $9.2 \%$ less in accessions that became assignments, but this was not significant; selecting a self was $-30.5 \%$ less in those crosses that made assignment, and this was significant (Table 7). Inbreeding lowers seedling vigor because of inbreeding depression. These results indicate that selfing appears to reduce the number of clones being advanced more than the percentage of off-types.

Table 7. Percent hybrid (H), selfs (S), and off-type (C) and the percent difference from the odds ratio of off-type to hybrid and self to hybrid for assigned to not assigned.

\begin{tabular}{cccccc}
\hline & & & \multicolumn{2}{c}{ Yes vs. No } \\
\hline Assigned & $\% \mathbf{H}+$ & \%S $\ddagger$ & $\% \mathbf{C ~} \S$ & $\mathbf{C} / \mathbf{H}$ & S/H \# \\
\hline Yes & 66.4 & 18.9 & 14.7 & $-9.2 \%$ & $-30.5 \%$ * \\
No & 60.5 & 24.8 & 14.7 & & \\
\hline
\end{tabular}

* Indicates significance at 95\% confidence; † Percent intentional hybrids; $\ddagger$ Percent selfing; § Percent off-types; Percent odds ratio of off-type to hybrid; \# Percent odds ratio of self to hybrid.

In this study, the fidelity of sugarcane seedlings from 361 biparental crosses was identified using SSR markers. The results showed that $58.4 \%$ of the seedlings were hybrids (Table 3); the remaining $41.6 \%$ were either selfs or off-types. Some crosses had no hybrids, such as H03-1614 and HB04-3152 (Table S1). The results are surprising and show that the hybrid level of the Louisiana sugarcane crosses were not high during those crossing years. The rate of hybridization between designated parents was less than that of a polycross found by Tew and Pan [10], who were able to identify 79-99\% of the polycross progeny as true hybrids; although the polycross was set up in an isolation booth, which would have reduced foreign pollen. Xavier et al. [11] also identified the male parent-specific SSR fingerprints in $73 \%$ of the progenies from polycrosses in lanterns with no selfing. In the literature, selfing rate is unpredictable and could have a genetic component. McIntyre and Jackson [9] identified $0 \%$ to $17.6 \%$ selfs among eight sugarcane crosses, but Melloni et al. [6] had a selfing rate of $85 \%$ in a 
polycross outside. McIntyre and Jackson [9] achieved this low selfing rate without female emasculation by selecting female parents with low pollen production. These crosses were also trimmed and made in pollen proof enclosures to reduce outcrossing. However, these were the results from a small number of crosses and the selfing rate was varied from cross to cross [6,9].

During crossing, flowers are classified as males by the amount of pollen they produce which is identified by a magnifier or pollen staining and microscope. Sometimes due to environmental conditions, flowers do not mature and open as expected. The low or infertile pollen production by selected male flowers and competitive pollen by the female may produce higher selfs. Hogarth [5], using Dudley's selfing model in lanterns to control pollen [27], found that accidental selfing might occur at $0-80 \%$ in a $5 \times 5$ sugarcane diallel cross. In this study, selfing numbers were higher than off-types, indicating that it may be a more important factor in the reduction of hybrid seed production; however, selfs are generally quickly eliminated from the breeding program because of poor performance related to inbreeding depression [28]. If a large percentage of selfs are planted, then land and labor resources are wasted. The off-types are probably produced when competitive males and open receptive female flowers are nearby. The female flowers may have some open and pollinated florets before being selected, and if these fertilized florets are not trimmed off before going into crossing cubicles, then a selfed or outcrossed seed could result. For crosses where commercial yield is important, and flowers are not heat treated because seed production is more important than seed hybrid fidelity, it is advised that wild and low sugar potential males be kept far away from the crossing bay to ensure that all off types are produced from high yielding parents. Since the time of this experiment, the U.S. sugarcane breeders have taken several steps to reduce selfing and outcrossing in breeding programs. At Canal Point, cloth barriers have been placed in front of the cubicles to reduce contamination by external pollen. The number of crosses that are hot water treated at Canal Point and Houma has increased to reduce selfing and outcrossing, and the open florets of females are trimmed off tassels to reduce non-controlled pollination.

\section{Conclusions}

The data from this study demonstrate the ability of SSR markers to identify the percentage of hybridization within crosses. The ratio of hybrids to off-types and selfs in the U.S. breeding programs during the 2002-2006 seasons was variable according to the location, year, and protocols used. Hot water treatment significantly lowered the ratio of off-types and selfs. Selfing appears to reduce advancement rates. Crosses with plants that were selected to be advanced and later to be assigned a new variety name had a significantly lower probability of selfing while the number of off-types was either not significantly different or significantly more in assignment crosses. It appears that selfing decreases advancement rates more than off-types and that both selfing and off-types can be reduced by trimming off dehisced florets and hot water treatment.

Supplementary Materials: The following are available online at http://www.mdpi.com/2073-4395/10/3/386/s1, Table S1: Identification of sugarcane cross seedling hybrids, selfs, and off-types in 2004 using SSR markers.

Author Contributions: Conceptualization, Y.-B.P.; methodology, Y.-B.P. and D.B.; software, D.B. and J.T.; validation, Y.-B.P and J.T.; formal analysis, J.T. and D.B.; investigation, Y.-B.P.; resources, Y.-B.P.; data curation, Y.-B.P. and J.T.; writing-original draft preparation, J.T. and Y.-B.P.; writing-review and editing, J.T., Y.-B.P., and D.B.; visualization, J.T. and Y.-B.P.; supervision, Y.-B.P.; project administration, Y.-B.P.; funding acquisition, Y.-B.P. All authors have read and agreed to the published version of the manuscript.

Funding: This research received no external funding.

Acknowledgments: We thank Thomas Tew, John Veremis, Kenneth Gravois, and Keith Bischoff for the crosses; and Dave Verdun, Lionel Lomax, Frances Adams, Elta Duet, Jennifer Chiasson, Cory Landry, Kathy Warnke, Jerri Magio, and Sheron Simpson for technical assistance.

Conflicts of Interest: The authors declare no conflicts of interest. 


\section{References}

1. Heinz, D.J.; Tew, T.L. Hybridization Procedures. In Sugarcane Improvement through Breeding; Elsevier: Amsterdam, The Netherlands, 1987; pp. 313-342.

2. Heinz, D.J. Sugarcane Improvement through Breeding; Developments in Crop Science; Elsevier: Amsterdam, The Netherlands, 1987; Volume 11.

3. Bischoff, K.P.; Gravois, K.A. The Development of New Sugarcane Varieties at the Lsu Agcenter. J. Am. Soc. Sugarcane Technol. 2004, 24, 142-164.

4. Moore, H.P.; Nuss, K.J. Flowering and Flower Synchronization. Sugarcane Improv. Breed. 1987, 11, $273-311$.

5. Hogarth, D.M. The Effect of Accidental Selfing on the Analysis of a Diallel cross with Sugar Cane. Euphytica 1980, 29, 737-746. [CrossRef]

6. Melloni, M.L.G.; Scarpari, M.S.; Pinto, L.R.; Perecin, D.; Xavier, M.A.; Landell, M.G.A. Selfing Rate Estimation in Sugarcane under Unfavorable Natural Conditions of Crossing by Using Microsatellite Markers. Genet. Mol. Res. 2014, 13, 2278-2289. [CrossRef]

7. Costa, P.M.A.; Almeida, C.F.; Silveira, G.; Soares, B.; Baffa, D.C.F.; Peternelli, L.A.; Bhering, L.L.; Barbosa, M.H.P. Selfing Confirmation in Sugarcane by Using Simple Sequence Repeat Markers, An Individual Reciprocal Recurrent Selection Scheme. Genet. Mol. Res. 2014, 13, 8962-8970. [CrossRef]

8. Santos, J.M.D.; Barbosa, G.V.D.; Neto, C.E.R.; Almeida, C. Efficiency of Biparental crossing in Sugarcane Analyzed by SSR Markers. Crop Breed. Appl. Biotechnol. 2014, 14, 102-107. [CrossRef]

9. McIntyre, C.L.; Jackson, P.A. Low Level of Selfing Found in a Sample of Crosses in Australian Sugarcane Breeding Programs. Euphytica 2001, 117, 245-249. [CrossRef]

10. Tew, T.L.; Pan, Y.-B. Microsatellite (Simple Sequence Repeat) Marker-Based Paternity Analysis of a Seven-Parent Sugarcane Polycross. Crop Sci. 2010, 50, 1401-1408. [CrossRef]

11. Xavier, M.A.; Pinto, L.R.; Fávero, T.M.; Perecin, D.; Carlini-Garcia, L.A.; Landell, M.G.A. Paternity Identification in Sugarcane Polycrosses by Using Microsatellite Markers. Genet. Mol. Res. 2014, 13, 2268-2277. [CrossRef]

12. Hack, S.M.; Huckett, B.I.; Butterfield, M.K. Application of Microsatellite Analysis to the Screening of Putative Parents of Sugarcane Cross Aa40. Proc. S Afr. Sug. Technol. Ass. 2002, 76, 232.

13. Litt, M.; Luty, J.A. A Hypervariable Microsatellite Revealed by in Vitro Amplification of a Dinucleotide Repeat within the Cardiac Muscle Actin Gene. Am. J. Hum. Genet. 1989, 44, 397.

14. Ruiz, C.; Breto, M.P.; Asins, M.J. A Quick Methodology to Identify Sexual Seedlings in Citrus Breeding Programs Using Ssr Markers. Euphytica 2000, 112, 89-94. [CrossRef]

15. Pan, Y.-B.; Liu, P.; Que, Y. Independently Segregating Simple Sequence Repeats (SSR) Alleles in Polyploid Sugarcane. Sugar Technol. 2015, 17, 235-242. [CrossRef]

16. Lu, X.; Zhou, H.; Pan, Y.; Chen, C.Y.; Zhu, J.; Chen, P.; Li, Y.R.; Cai, Q.; Chen, R.K. Segregation Analysis of Microsatellite (Ssr) Markers in Sugarcane Polyploids. Genet. Mol. Res. 2015, 14, 18384-18395. [CrossRef]

17. De Oliveira, A.C.; Garcia, A.N.; Cristofani, M.; Machado, M.A. Identification of Citrus Hybrids through the Combination of Leaf Apex Morphology and SSR Markers. Euphytica 2002, 128, 397-403. [CrossRef]

18. Cordeiro, G.M.; Taylor, G.O.; Henry, R.J. Characterisation of Microsatellite Markers from Sugarcane (Saccharum Sp.), a Highly Polyploid Species. Plant Sci. 2000, 155, 161-168. [CrossRef]

19. Xin, Z.; Velten, J.P.; Oliver, M.J.; Burke, J.J. High-Throughput DNA Extraction Method Suitable for PCR. Biotechniques 2003, 34, 820-827. [CrossRef]

20. Milligan, S.B.; Martin, F.A.; Bischoff, K.P.; Quebedeaux, E.O.; Dufrene, E.O.; Quebedeaux, K.L.; Hoy, J.W.; Reagan, T.E.; Legendre, B.L.; Miller, J.D. Registration of 'LCP 85-384' Sugarcane. Crop Sci. 1994, 34, 819-820. [CrossRef]

21. Pan, Y.-B. Databasing Molecular Identities of Sugarcane (Saccharum Spp.) Clones Constructed with Microsatellite (SSR) DNA Markers. Am. J. Plant Sci. 2010, 1, 87. [CrossRef]

22. Pan, Y.-B. Highly Polymorphic Microsatellite DNA Markers for Sugarcane Germplasm Evaluation and Variety Identity Testing. Sugar Technol. 2006, 8, 246-256. [CrossRef]

23. Tew, T.L.; Dufrene, E.O.; Garrison, D.D.; White, W.H.; Grisham, M.P.; Pan, Y.; Richard, E.P.; Legendre, B.L.; Miller, J.D. Registration of 'Hocp 00-950'sugarcane. J. Plant Regist. 2009, 3, 42-50. [CrossRef]

24. Stroup, W.W. Generalized Linear Mixed Models: Modern Concepts, Methods and Applications; CRC Press: Boca Raton, FL, USA, 2012.

25. SAS Institute. Base Sas 9.4 Procedures Guide; SAS Institute: Cary, NC, USA, 2014. 
26. Abu-Ellail, F.F.B.; McCord, P.H. Temperature and Relative Humidity Effects on Sugarcane Flowering Ability and Pollen Viability under Natural and Seminatural Conditions. Sugar Technol. 2019, 21, 83-92. [CrossRef]

27. Cockerham, C.C. Estimation of Genetic Variances. Stat. Genet. Plant Breed. 1963, 982, 53-94.

28. Silva, M.D.A.S.; Gonçalves, P.D.S. Inbreeding in Sugarcane Varieties. Ciência Rural 2011, 41, 580-586. [CrossRef] 